\title{
Evaluation of PPD response in patients with idiopathic arthritis who are on biological drug therapy
}

\author{
Kenan Barut ${ }^{1 *}$, Muhammet Köşker², Tugba Erener-Ercan', Haluk Cokugras², Yildiz Camcioglu², Necla Akcakaya², \\ Ozgur Kasapcopur ${ }^{1}$
}

From 21st European Pediatric Rheumatology (PReS) Congress

Belgrade, Serbia. 17-21 September 2014

\section{Introduction}

Juvenile idiopathic arthritis (JIA) is a disease most commonly presenting as peripheral arthritis, and increased inflammatory response due to endogenous and exogenous antigens plays a role in its pathogenesis. Tuberculin skin test (TST) is used to determine whether a person is infected with Mycobacterium tuberculosis. In studies, delayed type hypersensitivity response was found to be suppressed in vitro among JIA patients. TST in JIA patients was studied for the first time by our group. In that study, PPD response was found not to be affected by the distribution of subgroups of the disease, activity of the disease or treatment (methotrexate, prednisolone). None of the enrolled children in that study were using biological drugs.

\section{Objectives}

The aim of our study was to investigate the effect of biological drugs on PPD reaction mediated by Th1 immune response in a group of JIA patients who were not involved in our previous study.

\section{Methods}

The study group consisted of 234 patients with the diagnosis of JIA according to ILAR diagnostic criteria and who were using biological drugs, and 45 healthy controls. PPD of the patients which was routinely done during the follow up was obtained from the patient files. BCG vaccination status of the patients and controls was similar. PPD values $\geq 5 \mathrm{~mm}$ were considered positive. Subjects with a PPD $\geq 10 \mathrm{~mm}$ were evaluated with the suspicion of

'Pediatric Rheumatology, Istanbul University, Cerrahpasa Medical Faculty, Istanbul, Turkey

Full list of author information is available at the end of the article tuberculosis infection and those with the final diagnosis of tuberculosis infection were given anti-tuberculosis drug therapy.

\section{Results}

Of the 234 JIA patients on biological drug therapy, $102(43.6 \%)$ were male and $132(56.4 \%)$ were female. Age distribution was 3.25-19,8 years, mean age was $12.8 \pm$ 4.7 years. Disease duration ranged between 3 months and 17 years and mean duration of disease was $5.9 \pm$ 4.11 years. Mean diameter of PPD indurations' was $4,996 \pm 6,8494 \mathrm{~mm}$ (diameter: $0-40 \mathrm{~mm}$ ) in JIA patients and $7.83 \pm 3.47 \mathrm{~mm}$ (diameter $0-16 \mathrm{~mm}$ ) in controls $(\mathrm{p}=0,0056)$. PPD positivity was found in $96(\% 41)$ and 38 $(\% 84,4)$ of the subjects in JIA and control groups, respectively $(\mathbf{p}<\mathbf{0 , 0 0 0 1}) . \mathrm{PPD} \geq 10 \mathrm{~mm}$ was detected in $59(\% 25,2)$ and $19(\% 42,2)$ subjects of the JIA and control groups, respectively $(\mathbf{p}=\mathbf{0}, \mathbf{0 3})$. PPD was negative in $125(\% 53,4)$ and $3(\% 6,6)$ of the subjects in JIA and control groups, respectively $(\mathbf{p}<\mathbf{0 , 0 0 0 1})$. When $\mathrm{PPD}$ induration was reported with respect to the biological drugs that were used; PPD was $4.632 \pm 6.3490 \mathrm{~mm}$ in $185(79,1 \%)$ of the subjects using etanercept $(\mathrm{p}=0,01), 4.957 \pm 9.1873 \mathrm{~mm}$ in $23(9,8 \%)$ of the subjects using adalimumab $(\mathrm{p}=0,06)$, $8.391 \pm 7.7386 \mathrm{~mm}$ in $23(9,8 \%)$ of the subjects using infliximab $(\mathrm{p}=0,6)$ and $1.667 \pm 2.8868 \mathrm{~mm}$ in $3(1,3 \%)$ of the subjects using anakinra. There was no difference in PPD response between patients using etanercept and adalimumab. PPD induration was larger in subjects using Infliximab.

\section{Conclusion}

In patients with JIA who had infantile BCG vaccination and who were currently on biological drugs, PPD 
induration was significantly lower compared to the control group. There was no difference in PPD response between patients who were on biological drugs or who were not using drugs according to our two major studies. Prospective studies evaluating measurements of PPD reaction in patients on biological drug therapy would provide further information on this issue.

\section{Disclosure of interest}

None declared.

\section{Authors' details}

${ }^{1}$ Pediatric Rheumatology, Istanbul University, Cerrahpasa Medical Faculty, Istanbul, Turkey. ${ }^{2}$ Pediatric Infectious Disease, Istanbul University, Cerrahpasa Medical Faculty, Istanbul, Turkey.

Published: 17 September 2014

- Convenient online submission

- Thorough peer review

- No space constraints or color figure charges

- Immediate publication on acceptance

- Inclusion in PubMed, CAS, Scopus and Google Scholar

- Research which is freely available for redistribution 